\title{
DETERMINING THE SUITABILITY OF A BUSINESS PROCESS MODELLING TECHNIQUE FOR A PARTICULAR APPLICATION
}

\author{
R.W. Geyer ${ }^{1}$ \& C.J. Fourie ${ }^{2^{*}}$ \\ Department of Industrial Engineering \\ Stellenbosch University, South Africa \\ 14543249@sun.ac.za, ${ }^{2}$ cjf@sun.ac.za
}

\begin{abstract}
Organisations formally define and document their business processes in order to understand them and, subsequently, to enable continuous development, improvement, and management. Organisations can use business process modelling (BPM), which represents the design of graphical models that portray their business processes, to define and document their business processes formally. It is difficult, however, to select a suitable BPM technique in support of a specific application of BPM, owing to the considerable number of existing BPM techniques, the impact of their varying capabilities, and the lack of available formal measures to support evaluations of their suitability for specific modelling applications. This article presents a measurement framework to evaluate the usefulness of BPM techniques in specific modelling applications. It also presents the use of this measurement framework to determine an applicable BPM technique that can be applied in a specific modelling case.
\end{abstract}

\section{OPSOMMING}

Organisasies definieer en dokumenteer hulle besigheidsprosesse op 'n formele wyse om hulle prosesse te verstaan en gevolglik hulle deurlopende ontwikkeling, verbetering en bestuur te bemagtig. Ten einde die uitvoering van hierdie aktiwiteit aan te spreek, kan organisasies besigheidsprosesmodellering gebruik om grafiese modelle van hulle besigheidsprosesse te ontwerp. Daar word egter kennis geneem dat dit moeilik is om ' $n$ geskikte besigheidsprosesmodellering tegniek te kies ter ondersteuning van 'n spesifieke toepassing van besigheidsprosesmodellering. Dit is weens die groot hoeveelheid bestaande besigheidsprosesmodellering tegnieke, die impak van hulle verskillende vermoëns, asook die gebrek aan formele maatstawwe om toe te pas om hulle bruikbaarheid vir sekere modellering aanwendings te bepaal. Die artikel stel verder maatstawwe voor vir evaluering van die bruikbaarheid van besigheidsproses modellering tegnieke vir sekere modellering aanwendings. Dit wys ook die gebruik van hierdie metings raamwerk om 'n geskikte besigheidsproses modellering tegniek vir'n spesifieke modellering toepassing te bepaal.

Corresponding author 
Business process modelling (BPM) represents the collective use of certain methods, techniques, and tools in order to design, support, and manage business process models. These business process models are used to graphically define, document, and communicate the business processes of organisations. The popularity of business process models arises from their related benefits, which go beyond the basic ability to define and document business processes, and include the graphical portrayal of business process features such as inter-functional communication, resource requirements, and sequential constraints. It is suggested that the graphical portrayal of these types of features provides additional support for understanding, implementing, executing, measuring, analysing, improving, and controlling business processes. According to Mendling, business process models can be considered to be the conceptual artefacts underpinning the management of organisational processes [1]. In turn, BPM has evolved into a valuable approach to defining and documenting business processes [2], which are considered an important prerequisite for organisations that intend to engage in business process improvement and management initiatives [3].

\section{DIFFICULTY IN SELECTING A BUSINESS PROCESS MODELLING TECHNIQUE}

\subsection{Variety of business process modelling techniques}

A large variety of BPM techniques is available to support the application of BPM. They consist of different languages - and their related conventions, notations, and grammars that are applied to generate the graphical features and content of business process models. But the differences between these languages give rise to varying strengths and weaknesses pertaining to the use of each technique.

It becomes difficult to select a technique that can support a specific application of BPM, due to the impact of the considerable number of available techniques and their varying capabilities. Glassey observed that such a variety of techniques can be somewhat confusing, and the choice of an adequate technique for a given modelling project might be difficult [4]. In addition, current research efforts and application trends tend to suggest that there is no single technique that is consistently selected, or that is considered superior, for all modelling applications. With so many techniques, it becomes difficult to choose between them: no single technique stands out.

\subsection{Measuring the suitability of BPM techniques}

When selecting a BPM technique, the aim should be to identify and select one that is suitable for each specific modelling application. In order to identify and select such a technique, it is necessary to evaluate the suitability of all the techniques that are considered for the relevant application, based on the quality characteristics related to their graphical languages and their subsequent abilities to address the requirements of the specific modelling application.

However, these quality characteristics are often evaluated in an isolated, uncoordinated, inconsistent, and unclear manner. In relation to this, there are insufficient proposals concerning an approach to execute these evaluations, and a lack of formal measures to quantify properly the impact that these quality characteristics have on the abilities of their related techniques. Given these deficiencies, it becomes difficult to evaluate the suitability of the techniques that are considered for a specific modelling application. A tool to select the appropriate BPM technique could solve this problem.

\section{DEVELOPMENT OF A MEASUREMENT FRAMEWORK}

The more prominent quality characteristics related to the graphical languages of BPM techniques are dissected, arranged, and refined, to address the concerns mentioned above. Table 1 indicates these quality characteristics. 
Table 1: Quality characteristics of BPM techniques

\begin{tabular}{|c|c|}
\hline Quality characteristic & Description \\
\hline Completeness [5] & $\begin{array}{l}\text { Completeness is the ability of a BPM technique to design business } \\
\text { process models that can portray all the relevant business process } \\
\text { information required by an organisation. }\end{array}$ \\
\hline Complexity [6] & $\begin{array}{l}\text { Complexity is the degree to which a BPM technique designs business } \\
\text { process models that are difficult to design, understand, and use. }\end{array}$ \\
\hline Ease of generation [5] & $\begin{array}{l}\text { Ease of generation is the degree of ease associated with the design of } \\
\text { business process models using a specific BPM technique. }\end{array}$ \\
\hline Ease of understanding [5] & $\begin{array}{l}\text { Ease of understanding is the extent to which a BPM technique is able to } \\
\text { design business process models that are easy to understand. }\end{array}$ \\
\hline Ease of use [7] & $\begin{array}{l}\text { Ease of use is the ability of a BPM technique to design business process } \\
\text { models that are easy to use. }\end{array}$ \\
\hline Economy [8] & $\begin{array}{l}\text { Economy is the degree to which a BPM technique can design business } \\
\text { process models that portray all the relevant business process } \\
\text { information while using the minimum possible graphical elements. }\end{array}$ \\
\hline Effectiveness [9] & $\begin{array}{l}\text { Effectiveness is the degree to which a BPM technique can design } \\
\text { business process models that enable an organisation to achieve its } \\
\text { modelling objectives. }\end{array}$ \\
\hline Efficiency [9] & $\begin{array}{l}\text { Efficiency is the capability of a BPM technique to design business } \\
\text { process models by using the minimum possible number of resources. }\end{array}$ \\
\hline Expressiveness [9] & $\begin{array}{l}\text { Expressiveness is the degree to which a BPM technique is capable of } \\
\text { designing business process models for any number and type of } \\
\text { applications. }\end{array}$ \\
\hline Flexibility [9] & $\begin{array}{l}\text { Flexibility is the ability of a BPM technique to design business process } \\
\text { models that are easy to adapt in response to business process changes } \\
\text { that occur. }\end{array}$ \\
\hline Formality [9] & $\begin{array}{l}\text { Formality is the ability of a BPM technique to design business process } \\
\text { models that contain appropriate notations, conventions, and grammars } \\
\text { in aid of the differentiated portrayal of all relevant business process } \\
\text { elements. }\end{array}$ \\
\hline Software Support [10] & $\begin{array}{l}\text { Software support refers to the level of software support that can be } \\
\text { offered to a BPM technique during the design or subsequent use of its } \\
\text { associated business process models. }\end{array}$ \\
\hline Suitability [9] & $\begin{array}{l}\text { Suitability is the capability of a BPM technique to design business } \\
\text { process models that are considered appropriate for a specific } \\
\text { application. }\end{array}$ \\
\hline
\end{tabular}

\subsection{Measurements for quality characteristics}

\subsubsection{Suitability, effectiveness, and ease of use}

It is fair to argue that a BPM technique is eventually considered suitable if it possesses the capability to design and support business process models that enable the relevant organisation to achieve its modelling objectives. This implies that a BPM technique must first be regarded as effective before it can be regarded as suitable. In the same vein, we argue that a BPM technique is effective if it can design and support business process models that are complete, efficiently generated, easy to understand, and sustainable. Collectively, these four quality characteristics represent the ease with which a BPM technique can be used to design and support effective business process models. Given these arguments, it is necessary to determine the following characteristics of a BPM technique:

- $\quad$ ease of use, which can serve as an indication of its ability to design and support effective business process models; and 
- effectiveness, which can serve as an indication of its suitability for a specific modelling application.

Considering this from another perspective, the suitability of a BPM technique can be indicated by measuring its effectiveness. In turn, the effectiveness of a BPM technique can be indicated by measuring its ease of use. Ultimately, the ease of use associated with a BPM technique can be indicated by the weighted average of its related sub-measurements completeness, efficiency generation, ease of understanding, and sustainability.

\subsubsection{Completeness}

With reference to their modelling requirements, organisations identify specific processrelated information that must be portrayed by their business process models. Business process models that do not portray the required process-related information are eventually considered incomplete, and cannot be used effectively by their organisations.

The capability of a BPM technique to design and support complete business process models is therefore seen as a critical quality characteristic that should be measured and evaluated. Based on these views, completeness can be measured by examining a BPM technique's ability to design and support business process models that portray the required informational elements as determined by the scope of the relevant modelling application. The measurement for completeness is indicated by Table 2 .

Table 2: Measurement for completeness

\begin{tabular}{|c|l|}
\hline \multicolumn{2}{|c|}{ TXcomp $=\frac{\text { TXrinf }}{\text { orinf }}$, where } \\
\hline TXcomp & Completeness of BPM technique X, measured as a fraction. \\
\hline TXrinf & $\begin{array}{l}\text { Number of required informational elements portrayed by business process } \\
\text { models when they are designed through the use of BPM technique X. }\end{array}$ \\
\hline Orinf & $\begin{array}{l}\text { Number of required informational elements stipulated by the scope of the } \\
\text { modelling application. }\end{array}$ \\
\hline
\end{tabular}

\subsubsection{Ease of generation}

In relation to its ease of use, a BPM technique should enable designers easily to generate their required business process models. In contrast, designers intend to avoid BPM techniques when their use is considered tedious, time-consuming, and not sufficiently userfriendly. It is therefore important to measure the ease with which a designer can generate the required business process models for a specific modelling application when a specific BPM technique is used. This ease of generation can be determined through the use of the measurement indicated by Table 3.

Table 3: Measurement for ease of generation

\begin{tabular}{|c|l|}
\hline \multicolumn{1}{|l|}{ TXegen $=\frac{\text { TXrinf }}{\text { TXtime }}$, where } \\
\hline TXegen & $\begin{array}{l}\text { Ease of generation attributed to BPM technique X, measured as the created informational } \\
\text { elements per minute. }\end{array}$ \\
\hline TXrinf & $\begin{array}{l}\text { Number of required informational elements portrayed by business process models when they } \\
\text { are designed through the use of BPM technique X. }\end{array}$ \\
\hline TXtime & $\begin{array}{l}\text { Actual time taken to design the required business process models using BPM technique X, } \\
\text { measured in minutes. }\end{array}$ \\
\hline
\end{tabular}

\subsubsection{Efficiency and generating efficiency}

Organisations must achieve the objectives of their modelling projects using the minimum possible number of resources. This is necessary to ensure that the value of their modelling projects outweighs their inputs. Ultimately this is required in order to motivate the execution of these projects.

The efficiency of a modelling project can be influenced by various factors, which include 
the BPM methodologies, techniques and tools that are used to execute and support these projects. It is therefore argued that a BPM technique can only partially contribute to the overall efficiency of a modelling project. Similarly, the overall efficiency of a modelling project cannot be used as a direct reflection of the efficiency of a BPM technique.

So we need to define a new quality characteristic that reflects the isolated impact that a BPM technique can have on the overall efficiency of a modelling project. This new characteristic is defined as 'generating efficiency'; and it can be determined through the use of two types of measurements, both of them based on the ease of generation measurement. These two types are:

1. Single technique evaluation

This measurement compares the actual designer-related cost with the budgeted designerrelated cost of a modelling project, as indicated by Table 4 .

Table 4: Single technique measurement for generating efficiency

\begin{tabular}{|c|l|}
\hline \multicolumn{2}{|c|}{ TXegeff $=\frac{\text { TXtime } * \text { Crop }}{60 *(\text { Mrbud })}$, where } \\
\hline Txegeff & Generating efficiency of BPM technique X, measured as a fraction. \\
\hline Txtime & $\begin{array}{l}\text { Actual time taken to design the required business process models using BPM technique X, } \\
\text { measured in minutes. }\end{array}$ \\
\hline Crop & Designer's cost per hour. \\
\hline Mrbud & Budgeted designer-related cost as defined within the modelling budget. \\
\hline
\end{tabular}

2. Multiple technique evaluation

This measurement compares the generating efficiency of each of the evaluated techniques with the others. This measurement is indicated by Table 5 .

Table 5: Multiple technique measurement for generating efficiency

\begin{tabular}{|c|l|}
\hline \multicolumn{2}{|c|}{ TXegeff $=\frac{\text { TXegen }}{\operatorname{Max}\{T\{A ; B ; C ; \ldots . . ; X\} \text { egen }\}}$, where } \\
\hline TXegeff & Generating efficiency of BPM technique $\mathrm{X}$, measured as a fraction. \\
\hline Txegen & $\begin{array}{l}\text { Ease of generation attributed to BPM technique } \mathrm{X}, \text { measured as the created } \\
\text { informational elements per minute. }\end{array}$ \\
\hline $\mathrm{T}\{\mathrm{A} ; \mathrm{B} ; \mathrm{C} ; \ldots . . . . ; \mathrm{X}\}$ egen & Ease of generation attributed to each discrete alternative $\{\mathrm{A} ; \mathrm{B} ; \mathrm{C} ; \ldots . . . . \mathrm{X}\}$ \\
\hline
\end{tabular}

\subsubsection{Ease of understanding, complexity, and economy}

It is clear that to use business process models effectively, they must first be understood by their users. This suggests that a BPM technique must enable the design of business process models that are easy to understand. For this, it is necessary to formulate a measurement that can determine the ease with which users can understand business process models when they are designed through the use of a specific BPM technique. Two measurements are proposed in order to measure this ease of understanding. They are:

1. Practical measurement

The practical measurement involves the execution of a survey to determine the ease with which the relevant stakeholders can understand business process models when designed through the use of a specific BPM technique. This measurement can also be related to two types of evaluation and sub-measurement (single or multiple technique evaluation), indicated in Table 6 and Table 7 respectively. 
Table 6: Single technique measurement for practical ease of understanding

\begin{tabular}{|c|l|}
\hline \multicolumn{2}{|c|}{ TXeund $=\frac{\text { TXsund }}{\text { TXnund }}$, where } \\
\hline TXeund & Ease of understanding related to BPM technique X, measured as fraction. \\
\hline TXsund & $\begin{array}{l}\text { Count of all the survey participants who consider the business process models } \\
\text { related to BPM technique X as easy to understand, where "yes" =1 and "no" }=0\end{array}$ \\
\hline TXnund & $\begin{array}{l}\text { Count of all the survey participants who are asked to comment on the ease of } \\
\text { understanding related to BPM technique X. }\end{array}$ \\
\hline
\end{tabular}

Table 7: Multiple technique measurement for practical ease of understanding

\begin{tabular}{|c|c|}
\hline \multicolumn{2}{|r|}{$T$ Xeund $=\frac{T X c u n d}{\operatorname{Max}\{T\{A ; B ; C ; \ldots \ldots ; X\} \text { cund }\}}$, where } \\
\hline TXeund & Ease of understanding related to BPM technique $\mathrm{X}$, measured as a fraction. \\
\hline TXcund & $\begin{array}{l}\text { Count of all the survey participants who consider the business process models } \\
\text { related to BPM technique } X \text { as the easiest to understand of all the proposed } \\
\text { alternatives. }\end{array}$ \\
\hline $\mathrm{T}\{\mathrm{A} ; \mathrm{B} ; \mathrm{C} ; \ldots . . . . \mathrm{X}\}$ cund & $\begin{array}{l}\text { Count of all the survey participants who consider the business process models } \\
\text { related to modelling technique }\{\mathrm{A} ; \mathrm{B} ; \mathrm{C} ; \ldots . . . . ; \mathrm{X}\} \text { as the easiest to understand of } \\
\text { all the proposed alternatives. }\end{array}$ \\
\hline
\end{tabular}

2. Theoretical measurement

The theoretical measurement involves an evaluation of a BPM technique's ability to design business process models that are economical and of the least possible complexity. An increase in the number of informational elements portrayed by business process models is identified as increasing their complexity. In turn, an increase in the complexity of business process models decreases the ease with which they can be understood by their users.

It is understandable that certain modelling applications require a large number of informational elements that must be portrayed by their associated business process models. In order to address the requirements of these modelling applications, the design of complex business process models is, to some extent, unavoidable. In addition, these business process models will remain just as complex, regardless of the BPM technique that is used for their design. This can be considered an 'uncontrollable complexity' that is inherited by business process models from the requirements of their associated modelling applications.

The portrayal of additional informational elements beyond the requirements of modelling applications may indeed sometimes be useful; but most of the time they only clutter business process models with information that is not required. This leads to the design of uneconomical business process models that are considered too complex for the purposes of their associated modelling applications. The portrayal of these additional informational elements is the result of the BPM technique that is used to design the required business process models. These models inherit a 'controllable complexity' from the BPM technique that is used for their design.

Eventually, BPM techniques must be able to design complete business process models while still being able to ensure that they are economical and of the least possible 'controllable complexity'. This implies that the stipulated requirements for modelling applications should serve as the upper-limit for the informational elements that must be portrayed by their associated business process models. Based on these perspectives, the measurement indicated by Table 8 is defined to determine the economy associated with the use of a BPM technique for a specific modelling application. 
Table 8: Measurement for economy

\begin{tabular}{|c|l|}
\hline \multicolumn{2}{|c|}{ TXecon $=2-\left(\frac{\text { TXainf }}{\text { Orinf }}\right)$, where } \\
\hline TXecon & $\begin{array}{l}\text { Economy of BPM technique X, measured as a fraction. } \\
\text { If TXecon }>1, \approx 1\end{array}$ \\
\hline TXainf & $\begin{array}{l}\text { Number of all the informational elements that are portrayed by business process } \\
\text { models when designed using BPM technique X. }\end{array}$ \\
\hline Orinf & $\begin{array}{l}\text { Number of informational elements that must be portrayed, as stipulated by the scope } \\
\text { of the relevant modelling application. }\end{array}$ \\
\hline
\end{tabular}

This measurement of economy is used, therefore, to suggest the ability of a BPM technique to design business process models that are of the least possible 'controllable complexity'. Consequently, it is used as a theoretical measurement to determine the ease of understanding associated with the relevant BPM technique.

\subsubsection{Formality, expressiveness, flexibility, software support, and sustainability}

In order to standardise and sustain their modelling practices and outputs, it is important that organisations consistently use the same BPM technique for both their current and their future modelling projects. Evaluating the ease with which a BPM technique can be used should therefore not be limited to its current use: it should also include an evaluation of its future use, which is also considered significant. To measure this future use, it is necessary to define a new quality characteristic: the 'sustainability' of a BPM technique.

The initial modelling projects of organisations generally represent the design of business process models that portray their business processes at a high level of abstraction. As their business process maturities improve, organisations require business process models that can portray their business processes in more detail. In addition, the dynamic nature of organisations can lead to the need to modify their current business processes and, therefore, also the details included in their business process models. BPM techniques whose semantic definition is limited may struggle to address organisations' increasing or changing illustration requirements; and in the end the future usefulness of these techniques is limited.

The formality (how well the semantics are defined) of a BPM technique can therefore give insight into its capability to address organisations' possible increasing or changing illustration requirements. This implies that the formality of BPM techniques can be used to suggest both their expressiveness and their flexibility. Ultimately, the formality of BPM techniques represents a sub-measurement of their sustainability.

Understandably, the evaluation of a single technique's formality is difficult, given that it is impossible to predict accurately the specific illustration requirements of future modelling applications. And without the referencing platform provided by the comparison of multiple techniques, putting the formality of a specific technique into perspective becomes difficult. Based on these views, the formality of a BPM technique can be suggested by the measurement indicated by Table 9 .

Based on the increasing use of technology-based operations within organisations, it will become more and more important for BPM techniques to be able to integrate with the software systems used by organisations. In the interests of sustainability, it is also important to evaluate the software support that is available for BPM techniques within organisations. The following measurement related to software support is indicated by Table 10. 
Table 9: Measurement for formality

\begin{tabular}{|c|c|}
\hline \multicolumn{2}{|c|}{ TXform $=\frac{T X c s e m}{M a x\{T\{A ; B ; C ; \ldots . . ;\} \text { csem }\}}$, where } \\
\hline TXform & Level of formality related to BPM technique $X$, measured as a fraction. \\
\hline TXcsem & Count of all well-defined semantics related to BPM technique $X$. \\
\hline T\{A;B;C;.....;X\}csem & Count of all well-defined semantics related to BPM technique $\{A ; B ; C ; \ldots . . . ; X\}$. \\
\hline
\end{tabular}

Table 10: Measurement for software support

\begin{tabular}{|c|l|}
\hline \multicolumn{2}{|c|}{ TXsoft $=$ TXyint, where } \\
\hline TXsoft & $\begin{array}{l}\text { Software support related to BPM technique X, measured as a binary value }(0 \text { or } \\
1) .\end{array}$ \\
\hline TXyint & $\begin{array}{l}\text { Integration is possible between BPM technique X and the enterprise resource } \\
\text { planning (ERP) system that is used by the relevant organization; True }=1, \text { False } \\
=0\end{array}$ \\
\hline
\end{tabular}

\subsection{Measurement structure}

Based on the dissection, arrangement, and refinement of some of the more prominent quality characteristics of the graphical languages of BPM techniques, the measurement framework indicated by Figure 1 is suggested. Together with the formulated measurements, it can be used to evaluate the suitability of the BPM techniques that are considered for specific modelling applications.

\subsection{Measurement weights}

The measurements contained within this framework are assigned specific weights (top right corner of each measurement in Figure 1). These weights are assigned to the measurements based on one of two arguments:

1. The relevant measurement can be single-handedly used to measure its parent characteristic. Based on the earlier discussions, this includes the weights that are assigned to:

- effectiveness

- $\quad$ ease of use

- formality

- economy

- least complexity

2. It is possible that a biased weight distribution among a group of sub-measurements, coupled with higher measured capabilities in some (but not all) of these submeasurements, can give a false impression of the overall capability of their parent characteristic.

Table 11 serves as an example of such a false impression. Evaluating the ease of use of both these techniques, Technique 2 is identified as the technique with the higher capability for ease of use. This result is due to a biased weight distribution and a higher capability for its associated completeness. It can therefore be misinterpreted that Technique 2 is superior to Technique 1 in all the sub-measurements of ease of use - even though Technique 2 performed much worse than Technique 1 in three out of the four sub-measurements. 


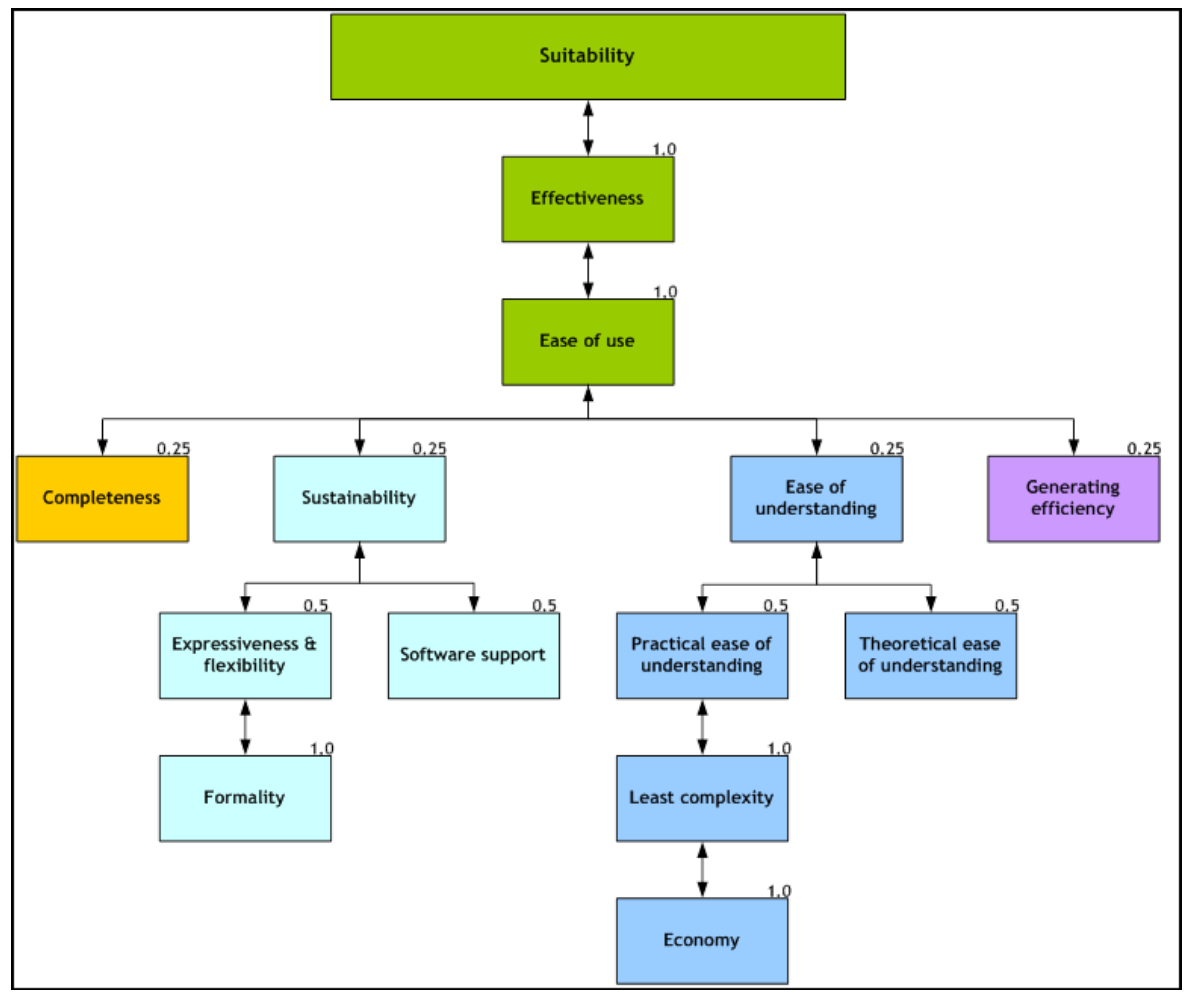

Figure 1: Measurement framework for BPM techniques

Table 11: Impact of biased weight distribution

\begin{tabular}{|c|c|c|c|c|c|c|}
\hline \multicolumn{7}{|c|}{ Biased Weight Distribution } \\
\hline \multirow{4}{*}{ Technique 1 } & & Completeness & Generating Efficiency & Ease of Understanding & Sustainability & \\
\cline { 2 - 8 } & Measured Capability & 0.65 & 0.65 & 0.65 & 0.65 & \\
\cline { 2 - 8 } & Weight & 0.25 & 0.25 & 0.25 & 0.25 & Total Ease of Use \\
\cline { 2 - 8 } & & & & & & 0.65 \\
\hline \multirow{4}{*}{ Technique 2 } & & Completeness & Generating Efficiency & Ease of Understanding & Sustainability & \\
\cline { 2 - 8 } & Measured Capability & 0.9 & 0.35 & 0.35 & 0.35 & \\
\cline { 2 - 8 } & Weight & 0.6 & 0.1 & 0.2 & 0.1 & Total Ease of Use \\
\cline { 2 - 8 } & & & & & & 0.68 \\
\hline
\end{tabular}

In order to eliminate the possibility of such misinterpretations, we argue that certain submeasurements represent a collective group that must have the same weights to validate the measurement of their parent characteristic. This is motivated by Table 12, which indicates the impact that a uniform weight distribution can have on the same evaluation.

Based on the earlier discussions, this includes the weights that are assigned to the following groups:

- completeness, sustainability, ease of understanding, and generating efficiency as a collective group of sub-measurements used to measure ease of use;

- $\quad$ software support and expressiveness and flexibility as a collective group of submeasurements used to measure sustainability; and

- theoretical ease of understanding and practical ease of understanding as a collective group of sub-measurements used to measure ease of understanding. 
Table 12: Impact of uniform weight distribution

\begin{tabular}{|c|c|c|c|c|c|c|}
\hline \multicolumn{7}{|c|}{ Uniform Weight Distribution } \\
\hline \multirow{4}{*}{ Technique 1} & & Completeness & Generating Efficiency & Ease of Understanding & Sustainability & \\
\hline & Measured Capability & 0.65 & 0.65 & 0.65 & 0.65 & \\
\hline & Weight & 0.25 & 0.25 & 0.25 & 0.25 & Total Ease of Use \\
\hline & & & & & & 0.65 \\
\hline \multirow{4}{*}{ Technique 2} & & Completeness & Generating Efficiency & Ease of Understanding & Sustainability & \\
\hline & Measured Capability & 0.9 & 0.35 & 0.35 & 0.35 & \\
\hline & Weight & 0.25 & 0.25 & 0.25 & 0.25 & Total Ease of Use \\
\hline & & & & & & 0.49 \\
\hline
\end{tabular}

\section{CASE STUDY: USE OF MEASUREMENT FRAMEWORK}

The developed measurement framework was used to determine a suitable BPM technique for a supermarket that forms part of a broader chain of supermarkets within South Africa. In order to maintain the required confidentiality, the supermarket is referred to as Supermarket X, and the broader chain of supermarkets is referred to as Chain X.

\subsection{Scope of modelling application}

Through collaboration with the project team of Chain $X$, it was established that the execution of the modelling project should have led to the design of business process models that can be used to understand and subsequently analyse the core business processes of Supermarket $X$. The designed business process models should also have provided a platform for future modelling efforts and for the roll-out of standard procedures across the various other supermarkets of Chain X. The business process models should ideally have portrayed the following informational elements:

- $\quad$ the events that start and end the activities within the core business processes

- $\quad$ the activities that are contained within the core business processes

- the sequences / interdependencies between the activities that are contained within the core business processes

- the responsibilities that are associated with the activities that are contained within the core business processes

- $\quad$ the resources and inputs that are used by the core business processes

- the outputs of the activities that are contained within the core business processes

- the customers of the outputs that are created by the core business processes

\subsection{Considered techniques}

The techniques that were considered for this application were BPM notation (BPMN), eventdriven process chains (EPCs), and unified modelling language activity diagrams (UML-AD). These techniques were used to design distinct sets of business process models respectively. The purpose of these distinct sets was to enable equivalent evaluations of the relevant techniques and their related abilities. These evaluations provided the platform to compare the considered techniques objectively for their suitability for the specific modelling application.

\subsection{Measurement results}

\subsubsection{Completeness, economy, and generating efficiency}

In order to measure the completeness, economy, and generating efficiency of each of the considered techniques, it was necessary to determine specific measurement inputs, which included the type and count of informational elements that were required, the informational elements that were portrayed by the distinct sets of business process models, and the time that was required to design the distinct sets of business process models.

The required type of informational elements was derived from the scope of the relevant modelling application. Through a count-based analysis of the business process descriptions, 
Table 13: Required informational elements

\begin{tabular}{|c|c|c|c|c|c|c|c|}
\hline \multirow{8}{*}{ 芌 } & & \multicolumn{6}{|c|}{ Required Informational Elements } \\
\hline & & $\begin{array}{c}\text { Events } \\
\text { Start / End }\end{array}$ & Activities & $\begin{array}{c}\text { Sequence or } \\
\text { interdependencies }\end{array}$ & $\begin{array}{l}\text { Customers or } \\
\text { responsible entities }\end{array}$ & Inputs & Outputs \\
\hline & Process 1 & 3 & 15 & 82 & 19 & 15 & 4 \\
\hline & Process 2 & 2 & 11 & 49 & 16 & 3 & 1 \\
\hline & Process 3 & 3 & 8 & 55 & 13 & 14 & 4 \\
\hline & Process 4 & 3 & 7 & 38 & 7 & 7 & 3 \\
\hline & Total & 11 & 41 & 224 & 55 & 39 & 12 \\
\hline & 381 & & & & & & \\
\hline
\end{tabular}

the counts of these required informational elements were determined. The results of this analysis are indicated in Table 13.

Through an analysis of the distinct sets of business process models, the following information relevant to the considered techniques was determined:

- The business process models that were designed through the use of BPMN portrayed all of the required informational elements.

- The business process models that were designed through the use of EPCs portrayed all of the required informational elements. They also portrayed intermediate events and their associated control flows. Using a count-based analysis of these intermediate events and associated control flows, the counts related to these informational elements were identified. These counts are indicated in Table 14.

- The business process models that were designed through the use of UML-AD portrayed all of the required informational elements except for customers or responsible entities. The counts related to these missing informational elements were derived from Table 13, and are indicated in Table 14.

Based on a time study, the time (in minutes) required to design the distinct sets of business process models was determined. Table 15 provides the results of this time study.

Table 14: Additional and missing informational elements

\begin{tabular}{|c|c|c|c|c|}
\hline \multirow{2}{*}{} & \multicolumn{2}{|c|}{ Additional informational elements- EPCs } & Missing informational elements-UML-AD \\
\cline { 2 - 5 } & Events intermediate & Sequence or interdependence & Customers or responsible entities \\
\cline { 2 - 5 } \\
\cline { 2 - 5 } & Process 1 & 14 & 14 & 19 \\
\cline { 2 - 5 } & Process 2 & 12 & 12 & 16 \\
\cline { 2 - 5 } & Process 3 & 12 & 12 & 13 \\
\cline { 2 - 5 } & Process 4 & 7 & 7 & 7 \\
\hline & Total & 45 & 45 & 55 \\
\hline
\end{tabular}

Table 15: Time required to design business process models

\begin{tabular}{|l|c|c|c|}
\hline & BPMN & EPC & UML-AD \\
\hline Process 1 & 63 & 88 & 59 \\
\hline Process 2 & 34 & 41 & 19 \\
\hline Process 3 & 36 & 73 & 42 \\
\hline Process 4 & 26 & 46 & 23 \\
\hline Total & $\mathbf{1 5 9}$ & $\mathbf{2 4 8}$ & $\mathbf{1 4 3}$ \\
\hline
\end{tabular}

Through the use of these measurements and measurement inputs, the completeness, economy, and generating efficiency of each of the BPM techniques was measured. Table 16 consolidates the results from these measurements. 
Table 16: Results for completeness, economy, and generating efficiency

\begin{tabular}{|c|c|c|c|}
\hline \multicolumn{4}{|l|}{ Completeness } \\
\hline & BPMN & EPC's & UML-AD \\
\hline Txrinf & 381 & 381 & 326 \\
\hline Orinf & 381 & 381 & 381 \\
\hline TXcomp = TXrinf /Orinf & 1.00 & 1.00 & 0.86 \\
\hline \multicolumn{4}{|l|}{ Economy } \\
\hline & BPMN & EPC'S & UML-AD \\
\hline Txainf & 381 & 471 & 326 \\
\hline Orinf & 381 & 381 & 381 \\
\hline TXecon =2-( TXainf /(Orinf )) & 1.00 & 0.76 & 1.00 \\
\hline \multicolumn{4}{|c|}{ Generating Efficiency } \\
\hline & BPMN & EPC's & UML-AD \\
\hline Txrinf & 381 & 381 & 326 \\
\hline Txtime & 381 & 381 & 326 \\
\hline Txegen & 2.40 & 1.54 & 2.66 \\
\hline TXegeff $=($ TXegen $) /(\operatorname{Max}\{T\{A ; B ; C ; \ldots . . . ; X\}$ egen $\})$ & 0.90 & 0.58 & 1.00 \\
\hline
\end{tabular}

\subsubsection{Ease of understanding}

Based on the relationship between the measurements of economy, least complexity, and theoretical ease of understanding, the economy of each of the considered techniques was used as a measure of their theoretical ease of understanding. To measure the practical ease of understanding, the results from the executed survey (multiple technique evaluation) were used as input for the measurement. Table 17 indicates the results from the survey.

Table 17: Results from practical survey

\begin{tabular}{|c|c|c|c|}
\hline & \multicolumn{3}{|c|}{ Preferred technique } \\
\hline & BPMN & EPCs & UML-AD \\
\hline Count & 4 & 0 & 21 \\
\hline Sample $n$ & \multicolumn{3}{|c|}{25} \\
\hline
\end{tabular}

Based on the results of the practical and theoretical ease of understanding measurements, the consolidated ease of understanding of each of the considered techniques was measured. Table 18 indicates the results of these measurements.

\subsubsection{Formality, software support, and sustainability}

In order to measure the formality relevant to each of the considered techniques, the following measurement inputs were identified:

- $\quad$ BPMN's full set of elements contains 37 well-defined semantics.

- $\quad$ EPC's extended set of elements contains 14 well-defined semantics.

- While collectively the UML family of languages possesses a rich set of semantics, only 12 well-defined semantics are relevant to UML-AD.

Table 18: Results for ease of understanding

\begin{tabular}{|c|c|c|c|}
\hline \multicolumn{4}{|c|}{ Theoretical ease of understanding } \\
\hline & BPMN & EPC's & UML-AD \\
\hline Txecon & 1.00 & 0.76 & 1.00 \\
\hline \multicolumn{4}{|c|}{ Practical ease of understanding } \\
\hline & BPMN & EPC's & UML-AD \\
\hline Txcund & 4 & 0 & 21 \\
\hline TXeund $=$ Txcund $/ \operatorname{Max}\{T\{A ; B ; C ; \ldots . . . ; X\}$ cund $\}$ & 0.19 & 0.00 & 1.00 \\
\hline \multicolumn{4}{|c|}{ Consolidated ease of understanding } \\
\hline & BPMN & EPC's & UML-AD \\
\hline$(0.5 *$ Practical $)+(0.5 *$ Theoretical $)$ & 0.60 & 0.38 & 1.00 \\
\hline
\end{tabular}


In order to measure the software support relevant to each of the considered techniques, the following information and measurement inputs were identified:

- $\quad$ Chain X uses SAP as its preferred enterprise resource planning (ERP) resource.

- $\quad$ BPMN can be integrated and supported by SAP.

- $\quad$ EPCS, as part of the ARIS Toolset, can be integrated and supported by SAP.

- $\quad$ Although various members of the UML family can be integrated and supported by SAP, UML-AD is currently not integrated or supported by SAP.

In light of the identified measurement inputs, the formality, software support, and sustainability of each the considered techniques were measured. The results of these measurements are indicated by Table 19.

Table 19: Results for formality, software support and sustainability

\begin{tabular}{|c|c|c|c|}
\hline \multicolumn{4}{|l|}{ Formality } \\
\hline & BPMN & EPC's & UML-AD \\
\hline Txsem & 1.00 & 0.38 & 0.32 \\
\hline \multicolumn{4}{|c|}{ Software Support } \\
\hline & BPMN & EPC's & UML-AD \\
\hline Txyint & 1 & 1 & 0 \\
\hline \multicolumn{4}{|l|}{ Sustainability } \\
\hline & BPMN & EPC's & UML-AD \\
\hline$(0.5 *$ Formality $)+(0.5 *$ Software Support $)$ & 1.00 & 0.69 & 0.16 \\
\hline
\end{tabular}

\subsubsection{Ease of use, effectiveness, and suitability}

Having completed these measurements, the measurements of ease of use, effectiveness, and suitability of each of the considered techniques were executed. These measures denoted a consolidation of all the other measured characteristics in conjunction with their assigned weight distributions. Table 20 indicates the ease of use, effectiveness, and suitability of each of the considered BPM techniques.

\section{CONCLUSIONS AND RECOMMENDATIONS}

This article has suggested that a BPM technique is eventually considered suitable if it possesses the capability to design and support business process models that enable the relevant organisation to achieve its modelling objectives. In turn, it has suggested that this requires the design and support of business process models that are complete, efficiently generated, easy to understand, and sustainable. Considering these perspectives and the results of the suitability evaluation, our suggestion is that:

- $\quad$ BPM notation (BPMN) is the more suitable technique for this specific modelling application; and

- $\quad$ the set of business process models that were designed using BPM notation signifies the more suitable representation of the business processes for this specific modelling application.

These suggestions are motivated by:

- $\quad$ BPMN's measured capability in effectiveness and ease of use for this specific modelling application; and

- $\quad$ BPMN's measured capability to generate efficiency, sustainability, completeness, and ease of understanding for this specific modelling application. 
Table 20: Results for ease of use, effectiveness, and suitability

\begin{tabular}{|c|c|c|c|c|c|c|c|}
\hline & $\begin{array}{c}\text { Characteristic } \\
\text { contribution to } \\
\text { overall suitability }\end{array}$ & $\begin{array}{c}\text { BPMN } \\
\text { result }\end{array}$ & $\begin{array}{c}\text { BPMN } \\
\text { contribution }\end{array}$ & $\begin{array}{c}\text { EPCs } \\
\text { result }\end{array}$ & $\begin{array}{c}\text { EPCs } \\
\text { contribution }\end{array}$ & $\begin{array}{c}\text { UML-AD } \\
\text { result }\end{array}$ & $\begin{array}{c}\text { UML-AD } \\
\text { contribution }\end{array}$ \\
\hline Software support & 0.1250 & 1.0000 & 0.1250 & 1.0000 & 0.1250 & 0.0000 & 0.0000 \\
\hline Formality & 0.1250 & 1.0000 & 0.1250 & 0.3800 & 0.0475 & 0.3200 & 0.0400 \\
\hline $\begin{array}{c}\text { Practical ease of } \\
\text { understanding }\end{array}$ & 0.1250 & 0.1900 & 0.0238 & 0.0000 & 0.0000 & 1.0000 & 0.1250 \\
\hline $\begin{array}{c}\text { Theoretical ease of } \\
\text { understanding }\end{array}$ & 0.1250 & 1.0000 & 0.1250 & 0.7600 & 0.0950 & 1.0000 & 0.1250 \\
\hline Economy & 0.1250 & 1.0000 & 0.1250 & 0.7600 & 0.0950 & 1.0000 & 0.1250 \\
\hline Completeness & 0.2500 & 1.0000 & 0.2500 & 1.0000 & 0.2500 & 0.8600 & 0.2150 \\
\hline Sustainability & 0.2500 & 1.0000 & 0.2500 & 0.6900 & 0.1725 & 0.1600 & 0.0400 \\
\hline Generating efficiency & 0.2500 & 0.9000 & 0.2250 & 0.5800 & 0.1450 & 1.0000 & 0.2500 \\
\hline Ease of understanding & 0.2500 & 0.6000 & 0.1500 & 0.3800 & 0.0950 & 1.0000 & 0.2500 \\
\hline Effectiveness & 1.0000 & 0.8750 & 0.8750 & 0.6625 & 0.6625 & 0.7550 & 0.7550 \\
\hline Ease of use & 1.0000 & 0.8750 & 0.8750 & 0.6625 & 0.6625 & 0.7550 & 0.7550 \\
\hline \multirow{2}{*}{ Suitability } & $\mathrm{BPMN}$ & $87.50 \%$ & & & & & \\
\cline { 2 - 7 } & $\mathrm{EPCs}$ & $66.25 \%$ & & & & & \\
\cline { 2 - 7 } & $\mathrm{UML}-\mathrm{AD}$ & $75.50 \%$ & & & & & \\
\hline
\end{tabular}

Considering that the various supermarkets of Chain $X$ should share the same strategic and operational objectives, it is fair to argue that their business processes should be the same. Given that assumption, it is also fair to argue that their modelling requirements should be the same. Based on these views, we suggest that:

- $\quad$ the business process models of Supermarket $X$ should be representative of the business process models of any of the other supermarkets of Chain X;

- the business process models of Supermarket $X$ can be used as a platform to standardise and roll out the relevant business processes to the various other supermarkets of Chain X; and

- $\quad$ the use of BPM notation to design and support business process models should lead to more suitable representation of the business processes of any of the other supermarkets of Chain X.

The proposed measurement framework worked well in evaluating the suitability of the techniques that were considered for the relevant modelling application. This framework should also be usable to evaluate the suitability of the techniques that are considered for other modelling applications. This is due to the fact that the designed measurements use variables that intentionally incorporate the relevant organisational characteristics and the requirements of the specific modelling applications. In other words, the measurements for completeness, generating efficiency, ease of understanding, and software support - along with their sub-measurements - are tailored to isolate the characteristics that impact the suitability of BPM techniques for specific modelling applications. We recommend that future research focus on further understanding how organisational characteristics impact the suitability of BPM techniques for specific modelling applications. We also recommend that a repository of scenarios be established where certain BPM techniques will be suitable for specific modelling applications

\section{REFERENCES}

[1] Mendling, J. 2008. Metrics for process models, Springer: Berlin / Heidelberg.

[2] Born, M., Brelage, C., Markovic, I., Pfeiffer, D. \& Weber, I. 2009. Auto-completion for executable business process models, Business process management workshops: Lectures notes in business information processing, 17(1), pp 510-515. 
[3] Indulska, M., Green, P., Recker, J. \& Rosemann, M. 2009. Business process modelling: Perceived benefits, Conceptual Modeling: Lecture Notes in Computer Science, 5829(1), pp 458471.

[4] Glassey, 0. 2008. A case study on process modeling - Three questions and three techniques, Journal of Decision Support Systems, 44(4), pp 842-853.

[5] Kock, N., Verville, J., Danesh-Pajou, A. \& Deluca, D. 2009. Communication flow orientation in business process modelling and its effect on redesign success: Results from a field study, Journal of Decision Support Systems, 46(2), pp 562-575.

[6] Sedera, W., Roseman, M. \& Doebeli, G. 2003. A process modelling success model: Insights from a case study, Proceedings of the $11^{\text {th }}$ European Conference on Information Systems, pp 1-11.

[7] Luo, W. \& Tung, Y.A. 1999. A framework for selecting business process modelling methods, Journal of Industrial Management and Data Systems, 99(7), pp 312-319.

[8] Luttighuis, P.O., Lankhorst, M., van de Wetering, R., Bal, R. \& van den Berg, H. 2001. Visualizing business processes, Journal of Computer Languages, 27(1-3), pp 39-59.

[9] Ying, C., Hong, L. \& Zhengchuan, X. 2004. An evaluation framework for inter-organizational business process modelling techniques, Proceedings of the 8th Pacific Asia Conference on Information Systems, pp 04-12, available from: http://www.pacis-net.org/file/2004/p04-12.pdf.

[10] Aldin, L. \& de Cesare, S. 2009. A comparative analysis of business process modelling techniques, Proceedings of the UK Academy for Information Systems (UKAIS) $14^{\text {th }}$ Annual Conference, available from: http://bura.brunel.ac.uk/handle/2438/4078. 